\title{
Diyabet Hastalarının Diyabetik Ayak Ülseri Hakkında Bilgi Düzeylerinin ve Ayak Bakımı Uygulamalarının Değerlendirilmesi
}

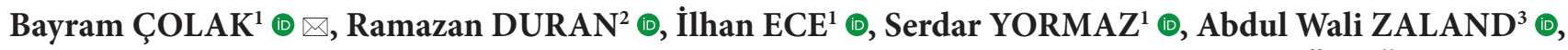 \\ Ersagun TAŞDELEN ${ }^{3} \oplus$, Nur Dilara SARIHAN ${ }^{3} \oplus$, Mehtap ARSLAN ${ }^{3} \oplus$, Merve Nur ÖZTÜRK ${ }^{3} \oplus$,

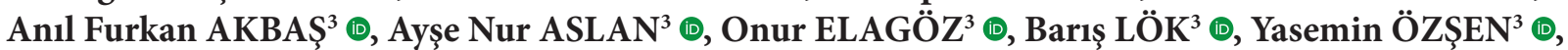 \\ Ceren ERSOY $^{3} \odot$, Furkan Necmettin $\mathrm{CAN}^{3} \oplus$, Kamile MARAKOĞLU ${ }^{2} \oplus$, Mustafa ŞAHIIN ${ }^{1} \oplus$ \\ ${ }^{1}$ Selçuk Üniversitesi Tip Fakültesi, Genel Cerrahi Anabilim Dalı, Konya, Türkiye \\ ${ }^{2}$ Selçuk Üniversitesi Tip Fakültesi, Aile Hekimliği Anabilim Dalı, Konya, Türkiye \\ ${ }^{3}$ Selçuk Üniversitesi Tip Fakültesi, Dönem 2 Öğrencisi, Konya, Türkiye \\ Çalışma için herhangi bir kaynak kullanılmamıştır. Üniversitemiz dönem 2 kanıta dayalı tıp grubu öğrencileri tarafından yapılmıştır. \\ Yazı daha önce herhangi bir toplantıda sunulmamıștır.
}

Bu makaleye yapılacak atıf: Çolak B ve ark. Diyabet Hastalarının Diyabetik Ayak Ülseri Hakkında Bilgi Düzeylerinin ve Ayak Bakımı Uygulamalarının Değerlendirilmesi. Türk Diyab Obez 2020;1: 22-29.

\begin{abstract}
ÖZET
Amaç: Diyabetin komplikasyonlarından birisi olan diyabetik ayak yarası (DAY) uzuv kayıpları ve hatta ölümle sonuçlanan önlenebilir bir tablodur. Diyabetik hastalara verilen eğitimlerle DAY gelişme oranı \%50 azaltılabilmektedir. Çalı̧mada diyabetik hastaların ayak bakımı hakkındaki bilgi düzeylerini ve bilgilendirilmiş hastaların doğru uygulama becerilerini ölçmeyi amaçladık. Ayrıca DAY gelişmiş hastaları da çalışmaya dahil ederek diyabetik ayak yarası gelişmesinde eğitimin önemini araştırmayı amaçladık.

Gereç ve Yöntemler: Aile hekimliği polikliniğinde diyabet eğitimi alan ve genel cerrahi kliniğinde DAY nedeniyle takip edilmiş diyabetik hastalar değerlendirildi. Hastalara DAY hakkındaki bilgi düzeylerini ve doğru uygulama düzeylerini ölçen soruları içeren anketler yapıldı. DAY gelişmiş ve gelişmemiş hastalar karşılaştırıldı.

Bulgular: Eğitim düzeyi düşük, sigara kullanan, 10 yıldan daha uzun süredir diyabetik olan, düzenli kontrole gitmeyen, kan şekeri regülasyonu sağlanamamış, günlük diyete uymayan, diyabet eğitimi almamış hastalarda DAY gelişme oranının istatistiksel olarak anlamlı düzeyde yüksek olduğu tespit edildi. DAY gelişmiş hastaların bilgi düzeyleri ölçümü anketine verdikleri cevapların ve günlük uygulamalarının da diğer hastalara göre istatistiksel olarak anlamlı düzeyde yanlış olduğu tespit edildi.

Sonuç: Hastalar, diyabetik ayak bakımı ile ilgili yeterli bilgi düzeyine sahip değiller. Diyabetik ayak eğitimi verilmiş kişilerde de bu bilgilerin gündelik hayatta uygulama oranı çok düşüktür. Bu durum diyabetik hastalarda tek başına DAY oluşma riskini artırmaktadır.

Anahtar Sözcükler: Diyabetik ayak, Anket
\end{abstract}

\section{Measurement of Diabetic Patients' Knowledge About Diabetic Foot Wound and Evaluation of Foot Care Practices}

\begin{abstract}
Aim: Diabetic foot ulcer (DFU), a complication of diabetes, is a preventable condition that results in limb losses and even death. With the training given to diabetic patients, DFU occurrence rate is reduced by $50 \%$. In this study, we aimed to measure the knowledge level of diabetic patients about foot care and the correct application skills of informed patients. In addition, we aimed to investigate the importance of education in the development of diabetic foot wound by including the patients with DFU in the study.
\end{abstract}

ORCID: Bayram Çolak / 0000-0003-1403-6963, Ramazan Duran / 0000-0001-8356-6269, İlhan Ece / 0000-0002-6966-7036, Serdar Yormaz / 0000-0002-6273-3643, Abdul Wali Zaland / 0000-0001-7535-3423, Ersagun Taşdelen / 0000-0003-2664-9345, Nur Dilara Sarihan / 0000-0001-5724-7715, Mehtap Arslan / 0000-0001-8812-7417, Merve Nur Öztürk / 0000-0003-2314-7841, Anıl Furkan Akbaş 0000-0001-5405-5187, Ayșe Nur Aslan / 0000-0002-2166-5194, Onur Elagöz / 0000-0002-8307-2899, Barıș Lök / 0000-0002-1553-4676, Yasemin Özşen / 0000-0002-3182-1157, Ceren Ersoy / 0000-0003-1715-1182, Furkan Necmettin Can / 0000-0002-9042-3845, Kamile Marakoğlu / 0000-0001-6510-8010, Mustafa Şahin / 0000-0002-5107-4101 
Material and Methods: Diabetic patients who received diabetes education in the family medicine clinic and who were followed up for DFU in the general surgery clinic were evaluated. Questionnaires about the level of knowledge about DFU and the level of correct application were applied to the patients about the level of knowledge about DAY and the level of correct application. The patients with DFU were compared with nonDFU patients.

Results: The rate of DFU was found to be significantly higher in the patients who had low level of education, who had been smoking, who had been diabetic for more than 10 years, who did not go to regular control, who could not regulate blood sugar, who did not meet daily diet, and who had not received diabetes education. It was found that the answers and daily practices of DFU-developed patients in their knowledge-level questionnaire were statistically significantly incorrect compared to the other patients.

Conclusion: Patients do not have enough knowledge about diabetic foot care. The rate of application of this information in daily life is very low in people who have been given diabetic foot training. This situation increases the risk of DFU occurrence in diabetic patients.

Key Words: Diabetic foot, Questionnaire

\section{GIIRIȘ}

Diyabetes mellitus (DM) tüm dünyada ve ülkemizde beraberinde ciddi komplikasyonların görüldüğü bir halk sağllğ̣1 problemidir. Dünya Sağlık Örgütü’nün verilerine göre dünyada 346 milyon diyabetik hastanın bulunduğu ve önlem alınmazsa bu sayının 2030 yılında ikiye katlanacağ 1 bilinmektedir (1). Ülkemizde diyabet prevalansı ile ilgili önemli çalışmalar Türkiye Diyabet Hipertansiyon Obezite ve Endokrinolojik Hastalıklar Prevalans Çalışması (TURDEP) 1 ve 2'dir. TURDEP 1, 1997-1998 y1lları arasında 24788 hastanın tarandığı bir çalışmadır. Bu çalışmada DM sıklığı \%7,2 olarak bildirilmiştir (2). 2010 yllında tamamlanan 26499 hastanın tarandığ 1 TURDEP 2 çalışmasında DM sıklığının \%7,2'den 13,7’ye yükseldiği tespit edilmiştir (2). DM sıklığındaki bu artış diyabetin komplikasyonlarını da beraberinde getirmektedir.

Diyabetin komplikasyonlarından birisi olan diyabetik ayak ülseri (DAÜ), mikroanjiopati ve nöropatinin neden olduğu ciddi bir tablodur. Ayrıca diyabetik hastaların hastaneye yatışlarındaki en önemli nedenlerdendir (3). Diyabetik hastaların yaşamları boyunca DAÜ ile karşılaşma oranı \%15-25 olarak belirtilmektedir (4). Travmatik olmayan ekstremite amputasyonlarının \%40-60'ını DAÜ oluşturmaktadır (5). Diyabetik ayak ülserine bağlı yapılan amputasyonlarla, diğer nedenlerden dolayı yapılmış amputasyonlar arasındaki en büyük farklılık, DAÜ’ye bağlı yapılan amputasyonların büyük ölçüde önlenebilir olmasıdır (6). Görüldüğü gibi DAÜ önlenebilir bir komplikasyondur. Ayrıca DAÜ nedeniyle yapılan majör amputasyonlar beraberinde mortaliteyi getirmektedir çünkü herhangi bir ekstremitesi ampute edilen diyabetik hastaların yaklaşık $\% 40$ 'ı beş yıl içinde kaybedilmektedir (7). DAÜ, diyabetik hastalarda uzuv kayılarına neden olması, enfeksiyon gelişmesi ile uzun tedavi süreçleri gerekmesi, hasta ve toplum için ekonomik yük oluşturması nedeniyle önlenmesi gereken ciddi toplumsal bir sorundur (8). DAÜ’nün engellenmesindeki en önemli unsur hastaların ayak bakımı davranışlarının düzeltilmesidir (9). Yapılan çalışmalarda diyabetik hastalarda diyabet ve ayak bakımı eğitiminin verilmesinin, yara oluşumunu ve amputasyon hızını azalttığı, bununla birlikte eğitimin yaralara bağlı morbiditeyi de $\% 50$ oranında düşürdügü gösterilmiştir (1011).

Çalışmada, DM tanısı almış hastaların ayak bakımı ile ilgili bilgi düzeylerinin değerlendirilmesi ve uygulamadaki yeterliliklerinin ölçülerek DAÜ gelişmesi üzerine etkilerinin araştırılması amaçlandı.

\section{GEREÇ ve YÖNTEMLER}

Bu çalışma, etik kurulumuzun 18.04.2018 tarihli ve 2018/149 sayılı kararı ile onaylanmıştır. Anket öncesinde hastaların onamı alınmıştır. Nisan 2018 - Mayıs 2018 tarihleri arasında Hastanemizin Aile Hekimliği Polikliniği’ne kontrol için başvuran DM tanısı almış hastalar ile Genel Cerrahi Kliniği'nde DAÜ nedeniyle cerrahi ve medikal tedavi almış DM hastaları çalışmaya dahil edildi.

\section{Çalışmaya Alınma Kriterleri}

Diyabetik hastalar (tip 2), diyabetik ayak ülseri nedeniyle tedavi edilmiş ve diyabetik ayak ülseri olan hastalar, 18 yaşından büyük hastalar, çalışmaya katılmaya gönüllü olmuş hastalar dahil edildi. Aile hekimliği polikliniğinde yeni tanı diyabet hastaları eğitim programına alınmakta ve altı ay sonra tekrar bilgi düzeyleri değerlendirilmektedir. Altı aylık süreçlerde kontrolleri devam etmektedir. Bu nedenle çalışmaya en az bir yıllık eğitim ve kontrol süresini tamamlamış hastalar dahil edildi.

\section{Çalışmadan Çıkarılma Kriterleri}

Çalışmaya katılmayı kabul etmeyen hastalar, diyabetik olmayan hastalar, diyabet dışı nedenlerle (vasküler yetmezlik gibi) ayak yarası oluşmuş hastalar, iletişim kurulamayacak düzeyde yaşlı ve bilinç durumu iyi olmayan hastalar, henüz yeni tanı almış, bir yıllık eğitim ve takip süresini tamamlamamış diyabetik hastalar (DM ve DAÜ hakkında henüz bilgi sahibi olmamaları nedeniyle) çalışmaya dahil edilmedi. 


\section{Anket Çalıșmasının Özellikleri}

Çalışmada uygulanan anket, literatür taramaları neticesinde araştırmacilar tarafindan oluşturulmuş toplam 36 sorudan oluşmakta idi. Anketin 14 soruluk kısmı hastaların demografik bilgilerini içermekte, 10 soru hastaların diyabetik ayak ülseri ile ilgili bilgi düzeyini ölçmekte ve 12 soru hastaların diyabetik ayak ülserini önlemek için uyguladıkları yöntemleri sorgulamakta idi. Anket, yüz yüze görüşme yöntemi ile hastalara uygulandı. Sorulara verilen doğru ve yanlış cevaplar değerlendirildi.

\section{İstatistiksel Değerlendirme}

Çalışmada elde edilen bulgular değerlendirilirken, istatistiksel analiz için Statistical Package for Social Sciences 20.0 programı kullanıldı. Sonuçlar \%95'lik güven aralığında, anlamlılık $\mathrm{p}<0,05$ düzeyinde değerlendirildi. Tanımlayıcı istatistikler, yüzde, ortalama, standart sapma, ortanca, minimum ve maksimum değerleri ile verilmiştir. Kategorik verilerin sıklık dağılımları verilerek, gruplar arasında kikare testi kullanıldı. İki ayrı grubun belli bir değişkene ait verilerini karşılaştırırken normal dağılan veriler için Student-t testi, normal dağılmayan veriler için MannWhitney U testi kullanıldı.

\section{BULGULAR}

Hastaların 56'sı (\%37,3) kadın, 94'ü $(\% 62,7)$ erkek, yaş ortalaması 55,7 $\pm 11,1$ idi. Hastaların demografik özellikleri Tablo 1'de görülmektedir. Hastaların diyabet tanısı aldıkları yaş ortalaması $43,7 \pm 12,0$ idi. Düzenli olarak bir sağlık kuruluşuna kontrole giden hasta sayısı $74(\% 49,3)$, verilen diyetlere uyan hasta sayısı 67 (\%44,7), herhangi bir zaman zarfında diyabet eğitimi almış hasta sayısı 67 (\%44,7), diyabet tanısı aldığ 1 süre boyunca yaşamının herhangi bir safhasında veya anket yapıldığı anda DAÜ gelişmiş ve DAÜ olan hasta sayısı 57 (\%38) idi. Hastaların ortalama açlık kan şekeri düzeyi $145 \pm 40,1 \mathrm{mg} / \mathrm{dL}$, ortalama HbA1c düzeyi $\% 7,86 \pm 1,5$ idi. Kan şekeri regülasyonu sağlanmış hasta sayıs1 51 (\%34) idi.

Hastaların diyabetik ayak bakımı ve DAÜ ile ilgili bilgi düzeyleri ölçüldüğünde; anket sorularına $\% 58,5$ oranında doğru yanıt verdikleri, ayak bakımında vazelin ve krem kullanımı, tırnakların düz kesilmesi, ayakkabı modeli seçimi gibi çeldirici bazı sorularda kararsız kaldıkları gözlendi. Günlük uygulamada ise hastaların ancak \%61,4’ünün doğru uygulamalarda bulundukları tespit edildi.

DAÜ olan hastaların \%64,9'u sigara içiyor iken, DAÜ olmayan hastaların \%18,3'ü sigara içiyordu $(\mathrm{p}<0,001)$.

DAÜ olan hastalar ile olmayan hastalar karşılaştırıldığında; cinsiyetin DAÜ gelişiminde anlamlı bir etken olmadığ 1 , DAÜ olan hastalarda; eğitim düzeyinin düşük, sigara kullanımının yüksek, diyabet sürelerinin uzun, kontrollerinin düzensiz, kan şekeri kontrollerinin sağlanamamış, günlük diyete uyumun olmadığı, daha önce diyabet eğitiminin alınmadığı tespit edildi $(\mathrm{p}<0,001)$. DAÜ gelişmiş hastaların bilgi düzeyleri ölçümü anketine verdikleri yanlış cevaplar istatistiksel olarak anlamlı düzeyde yüksekti (Tablo 2). DAÜ gelişmiş hastaların günlük uygulamalarındaki doğruluk düzeyi diğer hastalara göre istatistiksel olarak anlamlı düzeyde düşüktü (Tablo 3).

\section{TARTISSMA}

Diyabetik hastaların \%50'si, tüm yaşamları boyunca diyabetik ayak ülseri ile karşı karşıya kalma riski altındadır ve tüm dünyada yaklaşık her 30 saniyede bir diyabet nedeniyle ekstremite amputasyonu gerçekleştirilmektedir (12). Gelişen ve modern tedavi yöntemlerine rağmen diyabet hastalarının kronik komplikasyonları hâlâ önemli morbidite ve mortalite nedenlerindendir (13). Bu nedenle diyabetin en sık komplikasyonlarından olan diyabetik ayak ülserindan korunmada; hastalara gerekli eğitimlerin verilmesi ve ayak bakımlarını uygun şekilde yapmalarının sağlanması bu komplikasyondan korunmada en etkili yöntem olarak görülmektedir (14).

Diyabet eğitimleri esnasında hastalara ilk olarak diyabet kontrolü, diyet, egzersiz konularında eğitim verilmesi ayrıca bunların yanında mutlaka hastalara ayak hijyeni, ayak bakımı ve son olarak da ayakkabı seçimi ile ilgili eğitimlerin verilmesi önerilmektedir (15). Yine ayak bakımı ile ilgili eğitim verilmiş olan kişilerde, ayak sağlıkları için dikkat etmeleri gereken konuları daha iyi bildikleri tespit edilmiştir (8). Ancak asıl önemli nokta bilgi düzeylerinin yüksek olması değil, bu bilgilerin uygulanıyor olmasıdır. Çünkü yaptığımız çalışmada literatür ile benzer olarak diyabet eğitimi almış, diyabetik ayak ülseri riskleri ile ilgili yeterli bilgi düzeyine sahip kişilerde bile, mevcut bilgilerin gündelik hayatta uygulanmadığı tespit edildi (16). Çalışmada tüm hastaların \%44,7'sinin eğitim aldığı, DAÜ gelişmiş hastaların da \%26,9'unun eğitim aldığı fakat eğitim alanların \%85'inin bu bilgileri uygulamadığı tespit edildi.

Çalışmalarda 65 yaş üstü hastalarda diyabete bağlı komplikasyon gelişme riskinin, DAÜ gelişmiş olanlarda amputasyon riskinin, mikrosirkülasyonda bozulmanın yüksek olduğu belirtilmektedir $(17,18)$. Çalışmamızda da hastalar 65 yaş üzeri ve 65 yaş altı hastalar olarak değerlendirildi, fakat DAÜ gelişimi ile ilgili fark tespit edilmedi.

DAÜ ve ayak bakımının değerlendirildiği çalışmalarda, erkek cinsiyet ve düşük eğitim seviyesinin ayak bakımına dair bilgi düzeyindeki düşüklük ile ilişkili bulunmuştur (19). Bir başka çalışmada kadınlarda bilgi düzeyinin daha düşük olduğu tespit edilmiştir (20). Çalışmamızda da erkek hasta grubunda DAÜ görülme sıklığının yüksek olduğu tespit edilmiştir. Bu durumun, erkeklerin iş hayatında daha aktif olmalarina ve bu durumun da tekrarlayan travmalara, devamlı tahrişe maruz kalmaları neticesinde diyabetin komplikasyonları ile daha sık karşılaşmalarına neden olabileceği belirtilmektedir (21). 
Tablo 1: Diyabetik ayak ülseri olan ve olmayan hastaların diyabet, sosyodemografik ve sigara kullanım özellikleri.

\begin{tabular}{|c|c|c|c|c|c|c|c|}
\hline & \multicolumn{2}{|c|}{$\begin{array}{c}\text { Diyabetik ayak } \\
\text { ülseri olan hastalar }\end{array}$} & \multicolumn{2}{|c|}{$\begin{array}{l}\text { Diyabetik ayak ülseri } \\
\text { olmayan hastalar }\end{array}$} & \multirow[b]{2}{*}{ Toplam } & \multirow[b]{2}{*}{$\mathbf{X}^{2} / \mathbf{t}$} & \multirow[b]{2}{*}{$p$} \\
\hline & $\mathbf{n}$ & $\%$ & $\mathbf{n}$ & $\%$ & & & \\
\hline & \multicolumn{2}{|c|}{$\begin{array}{c}\text { Ort } \pm \text { SS/ } \\
\text { Ortanca(min-max) }\end{array}$} & \multicolumn{2}{|c|}{$\begin{array}{c}\text { Ort } \pm \text { SS/ } \\
\text { Ortanca(min-max })\end{array}$} & & & \\
\hline Yaş $(\text { Ort } \pm S D)^{* *}$ & \multicolumn{2}{|c|}{$56,23 \pm 10,95$} & \multicolumn{2}{|c|}{$55,46 \pm 11,29$} & & 49,630 & 0,167 \\
\hline \multicolumn{8}{|l|}{ Cinsiyet } \\
\hline Kadın & 14 & 24,5 & 42 & 45,1 & 56 & \multirow{2}{*}{0,408} & \multirow{2}{*}{0,684} \\
\hline Erkek & 43 & 75,5 & 51 & 54,9 & 94 & & \\
\hline \multicolumn{8}{|l|}{ Eğitim durumu } \\
\hline Okuryazar olmayan ve Okuryazar & 3 & 5,4 & 8 & 8,6 & 11 & \multirow{5}{*}{18,410} & \multirow{5}{*}{0,001} \\
\hline İlköğretim & 34 & 59,6 & 44 & 47,3 & 78 & & \\
\hline Ortaöğretim & 6 & 10,5 & 4 & 4,3 & 10 & & \\
\hline Lise & 14 & 24,5 & 15 & 16,1 & 29 & & \\
\hline Üniversite & 0 & 0,0 & 22 & 23,7 & $\mathbf{0}$ & & \\
\hline \multicolumn{8}{|l|}{ Medeni durum } \\
\hline Evli & 57 & 100,0 & 86 & 92,4 & 143 & \multirow{2}{*}{4,500} & \multirow{2}{*}{0,034} \\
\hline Bekar & 0 & 0,0 & 7 & 7,6 & 7 & & \\
\hline \multicolumn{8}{|l|}{ Sigara Kullanımı } \\
\hline Sigara kullanıyor & 37 & 64,9 & 17 & 18,3 & 54 & \multirow{3}{*}{34,475} & \multirow{3}{*}{$<0,001$} \\
\hline Hiç sigara kullanmamış & 17 & 29,8 & 54 & 58 & 71 & & \\
\hline Sigarayı bırakmış & 3 & 5,3 & 22 & 23,7 & 25 & & \\
\hline Diyabet tanısı aldığı yaş ${ }^{*}$ & \multicolumn{2}{|c|}{$35,00(22-68)$} & \multicolumn{2}{|c|}{$49,00(30-70)$} & & 91,220 & $<0,001$ \\
\hline 65 yaş ve altı & 34 & 59,6 & 62 & 67,7 & 96 & \multirow[b]{2}{*}{0,481} & \multirow[b]{2}{*}{0,488} \\
\hline 65 yaş üstü & 23 & 40,4 & 31 & 33,3 & 54 & & \\
\hline Diyabet tanısı aldığı süre* & \multicolumn{2}{|c|}{$17,00(3-24)$} & & & & 73,194 & $<0,001$ \\
\hline 5 yıl ve altında tanı alan & 2 & 3,5 & 35 & 37,6 & 37 & & \\
\hline 6-9 yıl arasında tanı alan & 10 & 17,5 & 36 & 38,7 & 46 & & \\
\hline 10 yıl ve üstü tanı alan & 45 & 79,0 & 22 & 23,7 & 67 & 46,035 & $<0,001$ \\
\hline Tedavi kontrolï & & & & & & & \\
\hline Düzenli kontrole giden hastalar & 4 & 7,0 & 70 & 75,2 & 74 & 63158 & -0001 \\
\hline Düzenli kontrole gitmeyen hastalar & 53 & 93,0 & 23 & 24,8 & 76 & 63,158 & $<0,001$ \\
\hline Açlık kan şekeri kontrolï* & $145,($ & 6-180) & 137 & $-172)$ & & 84,210 & 0,323 \\
\hline Açlık kan şekeri kontrolü sağlanmış hastalar & 9 & 15,8 & 42 & 45,2 & 51 & 13586 & $<0001$ \\
\hline Açlık kan şekeri kontrolü sağlanamamış hastalar & 48 & 84,2 & 51 & 54,8 & 99 & 10,500 & $<0,001$ \\
\hline Diyet uyumu & & & & & & & \\
\hline Diyete uyan hastalar & 4 & 7,0 & 63 & 67,7 & 67 & 50207 & -0001 \\
\hline Diyete uymayan hastalar & 53 & 93,0 & 30 & 32,2 & 83 & 30,291 & $<0,001$ \\
\hline Diyabet ve diyabetik ayak eğitimi & & & & & & & \\
\hline Diyabet ve diyabetik ayak eğitimi aldım & 18 & 31,5 & 49 & 52,6 & 67 & 5546 & 0019 \\
\hline Diyabet ve diyabetik ayak eğitimi almadım & 39 & 68,5 & 44 & 47,4 & 83 & 3,340 & 0,019 \\
\hline
\end{tabular}

*: Mann-Whitney U testi yapılmıştır. ${ }^{* *}$ : Student- $t$ testi yapılmıştır. 
Tablo 2: Diyabetik ayak ülseri olan ve olmayan hastaların, ayak bakımı ile ilgili bilgi düzeylerinin ölçümü anketine verdikleri cevapların dağılımları.

\begin{tabular}{|c|c|c|c|c|c|c|c|c|}
\hline & & \multicolumn{2}{|c|}{$\begin{array}{l}\text { Diyabetik ayak ülseri } \\
\text { gelișmiș hastalar }\end{array}$} & \multicolumn{2}{|c|}{$\begin{array}{l}\text { Diyabetik ayak ülseri } \\
\text { gelișmemiș hastalar }\end{array}$} & \multirow[b]{2}{*}{ Toplam } & \multirow[b]{2}{*}{$\mathrm{X}^{2} / \mathrm{t}$} & \multirow[b]{2}{*}{$p$} \\
\hline & & $\mathbf{n}$ & $\%$ & $\mathbf{n}$ & $\%$ & & & \\
\hline \multirow{5}{*}{$\begin{array}{l}\text { 1. Diyabetik hastalar } \\
\text { ayaklarını günlük } \\
\text { kontrol etmelidir. }\end{array}$} & Kesinlikle katılmıyorum & 1 & 1,7 & 5 & 5,3 & 6 & \multirow{5}{*}{23,931} & \multirow{5}{*}{$<0,001$} \\
\hline & Katılmiyorum & 19 & 33,3 & 11 & 11,8 & 30 & & \\
\hline & Kararsızım & 6 & 10,5 & 4 & 4,4 & 10 & & \\
\hline & Katılıyorum & 29 & 50,9 & 45 & 48,3 & 74 & & \\
\hline & Kesinlikle katıllyorum & 2 & 3,6 & 28 & 30,2 & 30 & & \\
\hline \multirow{5}{*}{$\begin{array}{l}\text { 2. Gün içinde ayak } \\
\text { kontrolü birden } \\
\text { fazla yapılmalıdır. }\end{array}$} & Kesinlikle katılmıyorum & 1 & 1,7 & 2 & 2,2 & 3 & \multirow{5}{*}{7,091} & \multirow{5}{*}{0,131} \\
\hline & Katılmiyorum & 20 & 35,1 & 20 & 21,5 & 40 & & \\
\hline & Kararsizım & 11 & 19,3 & 21 & 22,5 & 32 & & \\
\hline & Katıliyorum & 23 & 40,3 & 36 & 38,7 & 59 & & \\
\hline & Kesinlikle katılıyorum & 2 & 3,6 & 14 & 15,1 & 16 & & \\
\hline \multirow{5}{*}{$\begin{array}{l}\text { 3. Günlïk ayak } \\
\text { bakımı(vazelin, } \\
\text { krem, ayak } \\
\text { kremleri) } \\
\text { yapılmalıdır. }\end{array}$} & Kesinlikle katılmıyorum & 0 & 0 & 5 & 5,3 & 5 & \multirow{5}{*}{10,111} & \multirow{5}{*}{0,039} \\
\hline & Katılmiyorum & 17 & 29,8 & 19 & 20,4 & 36 & & \\
\hline & Kararsızım & 18 & 31,6 & 30 & 32,3 & 48 & & \\
\hline & Katıliyorum & 21 & 36,8 & 27 & 29,1 & 48 & & \\
\hline & Kesinlikle katılıyorum & 1 & 1,8 & 12 & 12,9 & 13 & & \\
\hline \multirow{5}{*}{$\begin{array}{l}\text { 4. Diyabetik } \\
\text { hastalar tırnaklarını } \\
\text { keserken diğer } \\
\text { kişilerden daha } \\
\text { dikkatli olmalıdır. }\end{array}$} & Kesinlikle katılmıyorum & 0 & 0 & 3 & 3,2 & 3 & \multirow{5}{*}{34,349} & \multirow{5}{*}{$<0,001$} \\
\hline & Katılmiyorum & 1 & 1,8 & 3 & 3,2 & 4 & & \\
\hline & Kararsizım & 23 & 40,3 & 8 & 8,6 & 31 & & \\
\hline & Katılıyorum & 31 & 54,4 & 47 & 50,5 & 78 & & \\
\hline & Kesinlikle katıliyorum & 2 & 3,5 & 32 & 34,5 & 34 & & \\
\hline \multirow{5}{*}{$\begin{array}{l}\text { 5. Diyabetik } \\
\text { hastaların yaraları } \\
\text { diğer kişilere göre } \\
\text { daha zor iyileşir. }\end{array}$} & Kesinlikle katılmıyorum & 0 & 0 & 3 & 3,3 & 3 & \multirow{5}{*}{14,148} & \\
\hline & Katılmiyorum & 0 & 0 & 5 & 5,4 & 5 & & \\
\hline & Kararsızım & 0 & 0 & 12 & 12,9 & 12 & & 0,007 \\
\hline & Katıliyorum & 27 & 47,3 & 35 & 37,6 & 62 & & \\
\hline & Kesinlikle katılıyorum & 30 & 52,7 & 38 & 40,8 & 68 & & \\
\hline 6. Evin içinde & Kesinlikle katılmıyorum & 0 & 0 & 4 & 4,3 & 4 & & \\
\hline diyabetik hastalar & Katılmiyorum & 24 & 42,1 & 12 & 12,9 & 36 & & \\
\hline her zaman & Kararsizım & 20 & 35,1 & 13 & 14,0 & 33 & 38,229 & $<0,001$ \\
\hline çorap veya terlik & Kat1lyyorum & 10 & 17,5 & 34 & 36,6 & 44 & & \\
\hline giymelidir. & Kesinlikle katılıyorum & 3 & 5,3 & 30 & 32,2 & 33 & & \\
\hline & Kesinlikle katılmıyorum & 1 & 1,8 & 18 & 19,4 & 19 & & \\
\hline hastalar istedikleri & Katılmiyorum & 4 & 7,0 & 24 & 25,8 & 28 & & \\
\hline If & Kararsızım & 31 & 54,4 & 21 & 22,6 & 52 & 29,169 & $<0,001$ \\
\hline ayakkabı modelını & Kat1lyyorum & 20 & 35,0 & 23 & 24,7 & 43 & & \\
\hline & Kesinlikle katıllyorum & 1 & 1,8 & 7 & 7,5 & 8 & & \\
\hline 8. Ayakkabıları & Kesinlikle katılmıyorum & 0 & 0 & 3 & 3,2 & 3 & & \\
\hline givmeden önce & Katılmiyorum & 27 & 47,4 & 9 & 9,7 & 36 & & \\
\hline & Kararsızım & 18 & 31,6 & 13 & 14,0 & 31 & 46,773 & $<0,001$ \\
\hline ner zaman komitro & Katıliyorum & 10 & 17,5 & 45 & 48,4 & 55 & & \\
\hline & Kesinlikle katılıyorum & 2 & 3,5 & 23 & 24,7 & 25 & & \\
\hline & Kesinlikle katılmıyorum & 0 & 0 & 2 & 2,2 & 2 & & \\
\hline 9. Diyabetik hastalar & Katılmıyorum & 0 & 0 & 6 & 6,5 & 6 & & \\
\hline ayak tırnaklarını & Kararsizım & 43 & 75,4 & 16 & 17,2 & 59 & 53,620 & $<0,001$ \\
\hline mutlaka düz & Katıliyorum & 13 & 22,8 & 45 & 48,4 & 58 & & \\
\hline Kesmenarr. & Kesinlikle katılıyorum & 1 & 1,8 & 24 & 25,7 & 25 & & \\
\hline 10. Diyabetik & Kesinlikle katılmıyorum & 0 & 0 & 4 & 4,3 & 4 & & \\
\hline hastalar ayakları ile & Katılmıyorum & 3 & 5,3 & 8 & 8,6 & 11 & & \\
\hline ilgili yaralanmada & Kararsızım & 13 & 22,8 & 22 & 23,7 & 35 & 25,859 & $<0,001$ \\
\hline mutlaka hastaneye & Katıliyorum & 38 & 66,6 & 26 & 28,0 & 64 & & \\
\hline başvurmalıdır. & Kesinlikle katıliyorum & 3 & 5,3 & 33 & 35,4 & 36 & & \\
\hline
\end{tabular}


Tablo 3: Diyabetik ayak ülseri olan ve olmayan hastaların, ayak bakımı ile ilgili doğru uygulama düzeylerinin ölçümü anketine verdikleri cevapların dağılımları.

\begin{tabular}{|c|c|c|c|c|c|c|c|c|}
\hline & & \multicolumn{2}{|c|}{$\begin{array}{l}\text { Diyabetik ayak ülseri } \\
\text { gelişmiş hastalar }\end{array}$} & \multicolumn{2}{|c|}{$\begin{array}{l}\text { Diyabetik ayak ülseri } \\
\text { gelişmemiş hastalar }\end{array}$} & \multirow[b]{2}{*}{ Toplam } & \multirow[b]{2}{*}{$\mathrm{X}^{2} / \mathrm{t}$} & \multirow[b]{2}{*}{$p$} \\
\hline & & $\mathbf{n}$ & $\%$ & $\mathbf{n}$ & $\%$ & & & \\
\hline \multirow{3}{*}{$\begin{array}{l}\text { 1. Evde kendiniz günlük ayak } \\
\text { bakımınızı yapıyor musunuz? }\end{array}$} & Evet & 6 & 10,5 & 52 & 55,9 & 58 & \multirow{3}{*}{64,031} & \multirow{3}{*}{$<0,001$} \\
\hline & Hayır & 51 & 89,5 & 21 & 22,6 & 72 & & \\
\hline & Bazen & 0 & 0 & 20 & 21,5 & 20 & & \\
\hline \multirow{3}{*}{$\begin{array}{l}\text { 2. Ayaklarınızı ılık sabunlu su } \\
\text { ile günlük yıkıyor musunuz? }\end{array}$} & Evet & 5 & 8,8 & 55 & 59,1 & 60 & \multirow{3}{*}{73,791} & \multirow{3}{*}{$<0,001$} \\
\hline & Hayır & 52 & 91,2 & 18 & 19,4 & 70 & & \\
\hline & Bazen & 0 & 0 & 20 & 21,5 & 20 & & \\
\hline \multirow{3}{*}{$\begin{array}{l}\text { 3. Tirnaklarınızı dïz ve } \\
\text { derinleşmeden mi kesersiniz? }\end{array}$} & Evet & 13 & 22,8 & 75 & 80,7 & 88 & \multirow{3}{*}{56,101} & \multirow{3}{*}{$<0,001$} \\
\hline & Hayır & 10 & 17,5 & 11 & 11,8 & 21 & & \\
\hline & Bazen & 34 & 59,7 & 7 & 7,5 & 41 & & \\
\hline \multirow{3}{*}{$\begin{array}{l}\text { 4. Ayaklarınızda oluşan } \\
\text { nasir, mantar gibi lezyonlara } \\
\text { kendiniz müdahale eder } \\
\text { misiniz? }\end{array}$} & Evet & 17 & 29,8 & 32 & 34,4 & 49 & \multirow{3}{*}{26,310} & \multirow{3}{*}{$<0,001$} \\
\hline & Hayır & 12 & 21,1 & 49 & 52,7 & 61 & & \\
\hline & Bazen & 28 & 49,1 & 12 & 12,9 & 40 & & \\
\hline \multirow{3}{*}{$\begin{array}{l}\text { 5. Ayağınızı ısıtmak için } \\
\text { sopa, sıcak su torbası, ısıtıcı } \\
\text { kullanır mısınız? }\end{array}$} & Evet & 7 & 12,3 & 14 & 15,0 & 21 & \multirow{3}{*}{45,174} & \multirow{3}{*}{$<0,001$} \\
\hline & Hayır & 20 & 35,1 & 74 & 79,6 & 94 & & \\
\hline & Bazen & 30 & 52,6 & 5 & 5,4 & 35 & & \\
\hline \multirow{3}{*}{$\begin{array}{l}\text { 6. Ayakkabı alırken diyabetik } \\
\text { hastalar için uygun ayakkabıyı } \\
\text { seçer misiniz? }\end{array}$} & Evet & 7 & 12,3 & 42 & 45,2 & 49 & \multirow{3}{*}{42,705} & \multirow{3}{*}{$<0,001$} \\
\hline & Hayır & 15 & 26,3 & 40 & 43,0 & 55 & & \\
\hline & Bazen & 35 & 61,4 & 11 & 11,8 & 46 & & \\
\hline \multirow{3}{*}{$\begin{array}{l}\text { 7. Ayakkabılarınızı giymeden } \\
\text { önce mutlaka kontrol eder } \\
\text { misiniz? }\end{array}$} & Evet & 3 & 5,3 & 55 & 59,1 & 58 & \multirow{3}{*}{49,345} & \multirow{3}{*}{$<0,001$} \\
\hline & Hayır & 47 & 82,5 & 25 & 26,9 & 72 & & \\
\hline & Bazen & 7 & 12,2 & 13 & 14,0 & 20 & & \\
\hline & Evet & 12 & 21,1 & 11 & 11,8 & 23 & & \\
\hline 8. Ayakkabılarınızı çorapsız & Hayır & 5 & 8,7 & 71 & 76,4 & 76 & 69,195 & $<0,001$ \\
\hline & Bazen & 40 & 70,2 & 11 & 11,8 & 51 & & \\
\hline & Evet & 6 & 10,5 & 62 & 66,7 & 68 & & \\
\hline 9. Ev içerisinde mutlaka çorap & Hayır & 50 & 87,7 & 19 & 20,4 & 69 & 64,424 & $<\mathbf{0 , 0 0 1}$ \\
\hline & Bazen & 1 & 1,8 & 12 & 12,9 & 13 & & \\
\hline & Evet & 23 & 40,4 & 52 & 55,9 & 75 & & \\
\hline 10. Günlükk çorap değiştirir & Hayır & 13 & 22,8 & 23 & 24,7 & 36 & 5,923 & 0,052 \\
\hline & Bazen & 21 & 36,8 & 18 & 19,4 & 39 & & \\
\hline 11. Ayaklarınızı yıkadıktan & Evet & 9 & 15,8 & 39 & 41,9 & 48 & & \\
\hline sonra mutlaka parmak & Hayır & 14 & 24,6 & 40 & 43,0 & 54 & 32,854 & $<0,001$ \\
\hline aralarını kurutur musunuz? & Bazen & 34 & 59,6 & 14 & 15,1 & 48 & & \\
\hline & Evet & 0 & 0 & 2 & 2,2 & 2 & & \\
\hline 12. Ayak bakımı esnasında & Hayır & 56 & 98,2 & 87 & 93,5 & 143 & 1,995 & 0,369 \\
\hline & Bazen & 1 & 1,8 & 4 & 4,3 & 5 & & \\
\hline
\end{tabular}

Cinsiyet ile bilgi düzeyi arasında tam bir ilişki kurulamamış olsa da kişilerin eğitim düzeylerinin yüksek olması ile diyabetik ayak hakkındaki bilgi düzeyleri ve davranışları arasında doğru ilişki olduğu tespit edilmiştir $(20,22)$. Çalışmada, diyabetik ayak ile ilgili doğru bilgiye sahip kişilerin büyük çoğunluğunun lise ve üniversite mezunu hastaların olduğu tespit edildi. Ayrıca diyabetik ayak ülseri gelişmiş ve tedavi görmüş hastaların genelinin ilkokul mezunu olduğu gözlendi (\%60). 
Hastaların diyabet tanısı aldıkları süre ile ayak bakımı bilgi düzeyleri arasında pozitif ilişki tespit edilmiştir $(19,23)$. Çalışmada diyabet süresi ile bilgi düzeyleri arasında istatistiksel olarak anlamlı bir ilişki tespit edilmedi. Fakat diyabet süresinin artması ile DAÜ oluşma riskinin de arttığı tespit edildi. Çalışmada bu hastaların özellikle kan şekeri regülasyonu sağlanamamış, kontrolsüz diyabeti olan hastalar olduğu tespit edildi.

Sigara içiminin diyabetik ayak ülseri oluşumunda önemli bir etken olduğu bilinmektedir (24). HgbAlc düzeyindeki \%1'lik azalmanın bile DM ilişkili komplikasyonlarda \%21, vasküler komplikasyonlarda \%37 oranında azalmaya neden olduğu bildirilmiştir (25). Çalışmada sigara içen, kan şekeri regülasyonu sağlanamamı̧, düzenli kontrole gitmeyen ve diyetine uymayan hastalarda DAÜ oranının anlamlı olarak yüksek olduğu gözlendi.

Diyabetik hastaların ayak bakımı hakkındaki eğitim düzeylerinin ölçüldügü çalışmalarda; hasta eğitiminin DAÜ oluşmasını ve amputasyon riskini azalttığı (15), eğitimin bilgi düzeyine ve uygulamaya olumlu etkilerinin olduğu (26), 20 dakikalık yüz yüze yapılan eğitimin etkili bir yöntem olduğu (27), üç ve daha fazla eğitim programına katılmış kişilerin hiç eğitim almamış veya bir defa eğitim almış kişilere göre daha iyi bilgiye ve uygulama düzeyine sahip oldukları (28), doktorlar tarafından verilen eğitimlerin daha etkili olduğu (29) birçok çalışmada belirtilmiştir. Tüm bu olumlu sonuçlara rağmen eğitim çalışmalarının incelendiği derlemelerde, eğitimlerin DAÜ gelişimini azalttığına dair yeterli kanıt olmadığı bildirilmiştir (29). Çalışmada diyabetik ayak ülseri gelişmiş ve bunun için yakın zamanda minör ya da majör amputasyon yapılmış hastalar ile DAÜ gelişmemiş hastaları karşılaştırdığımızda; DAÜ gelişmiş kişilerin yeterli düzeyde eğitim almamış oldukları, bilgi düzeylerinin düşük olduğu, yanlış uygulamaların sık olduğu, doğru uygulamaları bilmedikleri ve bu oranın DAÜ gelişmemiş gruptan anlamlı olarak yüksek olduğu tespit edildi.

Anket çalışmasının DAÜ olan ve olmayan diyabetik hastalara ayrı ayrı yapılmış olması, DAÜ oluşmasındaki risklerin ortaya koyulmasını sağlamıştır. Fakat hasta sayısının az olması çalışmanın olumsuz yönlerindendir.

\section{SONUÇ}

Diyabetik hastalar, diyabetik ayak bakımı ile ilgili yeterli bilgi düzeyine sahip değiller. Diyabet ve diyabetik ayak eğitimi verilmiş kişilerde de bu bilgilerin gündelik hayatta uygulama oranı çok düşüktür. Diyabetik ayak ülseri olan hastaların bilgi düzeylerinin düşük olması, eğitim almış hastaların da bilgilerini günlük uygulamalarına geçirememiş olmaları, tek başına DAÜ oluşmasını ve amputasyon riskini artırmaktadır. Özellikle DAÜ olan ileri yaşlı hastalar, sigara kullanımına devam edenler, kan şekeri regülasyonu için düzenli kontrole gitmeyenler, diyabetik ayak ülserinden korunmak için yetersiz bilgiye sahip ve yanlış uygulamalarda bulunan kişilerde eğitime daha önem verilmeli, gerekirse tekrarlayan eğitimlerle bilgi düzeyinin artırılmasının yanında doğru uygulamaların sağlanması gerekmektedir. Diyabet eğitiminin yanında hastalara mutlaka diyabetik ayak bakımı eğitimi de verilmelidir.

Teşekkürr

$\mathrm{Bu}$ çalışmayı yapmamız için bizlere imkân sunan Selçuk Üniversitesi Tip Fakültesi Aile Hekimliği Anabilim Dalı’na, özverili çalışmalarından dolayı Dönem 2 öğrencilerimize teşekkür ederiz.

\section{Çıkar Çatışması}

Yazarların çıkar çatışması yoktur.

Finansal Destek

Çalışma için finansal destek alınmamıştır.

Yazarların Makaleye Katkı Beyanı

Çalışma konusunun belirlenmesi, literatür taraması, çalışmanın düzenlenmesi (\%30): Bayram Çolak, Anketlerin düzenlenmesi ve istatistik çalışmaların yapılması (\%20): Ramazan Duran, Çalışmanın yazım aşamasında literatür araştırması ve çalışmanın tartışma kısmının yazımı (\%20): İlhan Ece ve Serdar Yormaz, Hastalarla görüşülmesi ve genel bilgilerin alınması, anketlerin yapılması (\%20); dönem 2 öğrencileri (Abdul Wali Zaland, Ersagun Taşdelen, Nur Dilara Sarıhan, Mehtap Arslan, Merve Nur Öztürk, Anıl Furkan Akbaş, Ayşe Nur Aslan, Onur Elagöz, Barış Lök, Yasemin Özşen, Ceren Ersoy, Furkan Necmettin Can), Çalışma istatistiğinin değerlendirilmesi ve düzenlenmesi (\%5): Kamile Marakoğlu, Çalışmanın son gözden geçirilmesi süreci (\%5): Mustafa Şahin.

\section{KAYNAKLAR}

1. World Health Organization (WHO). Diabetes Mellitus, 2017. Erişim: 15.01.2018. http:// www.who. int/mediacentre/ factsheets/fs312/en/.

2. Satman I, Omer B, et al. Twelve-year trends in the prevalence and risk factors of diabetes and prediabetes in Turkish adults. Eur J Epidemiol. 2013;28(2):169-180.

3. Lavery LA, Peters EJ, et al. Reevaluating the way we classify the diabetic foot: Restructuring the diyabetic foot risk classification system of the International Working Group on the diyabetic foot. Diabetes Care. 2008;31(1):154-156.

4. Boulton AJ, Vileikyte L, et al. The global burden of diabetic foot disease. Lancet. 2005;366:1719-1724.

5. Reiber GE, Vileikyte L, Boyko EJ, del Aguila M, Smith DG, Lavery LA, Boulton AJ. Causal pathways for incident lowerextremity ulcers in patients with diabetes from two settings. Diabetes Care. 1999;22(1):157-162. 
6. Tentelouris N, Al-Sabbagh S, et al. Mortality in diabetic and nondiabetic patients after amputations performed from 1990 to 1995. Diabetes Care. 2004;27:1598-1604.

7. Armstrong DG, Cohen $\mathrm{K}$, et al. Diabetic foot ulcers and vascular insufficiency: Our population has changed, but our methods have not. J Diabetes Sci Technol. 2011;5:1591-1595.

8. Dorresteijn JA, Kriegsman DM, et al. Patient education for preventing diabetic foot ulceration. Cochrane Database Syst Rev. 2014;16(12):CD001488.

9. Anselmo MI, Nery M, et al. The effectiveness of educational practice in diyabetic foot: A view from Brasil. Diabetol Metab Syndr. 2010;2(1):45.

10. Demiraslan H, Karaca Z, et al. Diyabetik ayak ülserleri. Turkiye Klinikleri J Endocrin-Special Topics. 2008;1(1).

11. Ortegon MM, Redekop WK, et al. Cost-effectiveness of prevention and treatment of the diabetic foot. Diabetes Care. 2004; 27:901-907.

12. Mata-Cases M, Roura-Olmeda P, et al: Grup d'Estudi de la Diabetis a l'AtencióPrimària de Salut, Catalonian Society of Familyand Community Medicine). Fifteen years of continuous improvement of quality care of type 2 diabetes mellitus in primary care in Catalonia, Spain. Int J Clin Pract. 2012;66:289298.

13. Gordois A, Scuffham P, et al. The health care costs of diabetic peripheral neuropathy in the US. Diabetes Care. 2003;26:17901795.

14. Batkın D, Çetinkaya F. Diabetes mellitus hastalarının ayak bakımı ve diabetik ayak hakkındaki bilgi, tutum ve davranışları. Sağlık Bilimleri Dergisi. (Journal of HealthSciences) 2005;14:612.

15. Nather A, Cao S, et al. Prevention of diabetic foot complications. Singapore Med J 2018;59(6):291-294.

16. Barbui EC, Cocco MI. Knowledge of the diabetic patient on foot care. Rev Esc Enferm USP. 2002;36:97-103.

17. Jan YK, Struck BD, et al. Foot care knowledge and practices and the prevalence of peripheral neuropathy among people with diabetes attending a secondary care rural hospital in Southern India. J Family Med Prim Care. 2013;2(1):27-32.
18. Timar-Banu O, Beauregard $\mathrm{H}$, et al. Development of noninvasive and quantitative methodologies for the assessment of chronic ulcers and scars in humans. Wound Repair Regen. 2001;9(2):123-132.

19. Desalu OO, Salawu FK, et al. Diabetic foot care: Self reported knowledge and practice among patients attending three tertiary hospitalin Nigeria. Ghana Med J. 2011;45(2):60-65.

20. Yastı AÇ, Kendirci M, et al. Diyabetik ayak yaralı hastaların ayaktan takibi ve sonuçları. S.B Ankara Eğitim ve Araştırma Hastanesi Tip Dergisi. 2012;45(3):100-104.

21. Abu-Qamar MZ. Knowledge and practice of foot self-care among Jordanians with diabetes: An interview-based survey study. J Wound Care. 2014;23(5):247-250.

22. Aypak C, Koç A, et al. Diyabetik ayak bakımı: Aile hekimliği polikliniğine başvuran hastalar tarafından bildirilen uygulama durumu. Cumhuriyet Tip Dergisi. 2012;34:423-428.

23. Müftüoğlu O, Karatürk N, et al. Diabetik ayak enfeksiyonları; Bakteriolojik analiz. Türk Diabet Yıllığı. 1988-1989;7:7-15.

24. Lasker RD. The diabetic control and complications trial. Implications for policy and practice. N Eng J Med. 1993;329(14):1035-1036.

25. Hasnain S, Sheikh NH. Knowledge and practices regarding foot care in diabetic patients visiting diabetic clinic in Jinnah Hospital, Lahore. J Pak Med Assoc. 2009;59(10):687-690.

26. Vatankhah N, Khamseh ME, et al. The effectiveness of foot care education on people with type 2 diabetes in Tehran, Iran. Prim Care Diabetes. 2009;3(2):73-77.

27. Schmidt S, Mayer H, et al. Diabetes foot self-care practices in the German population. J Clin Nurs. 2008;17(21):2920-2926.

28. Donohoe ME, Fletton JA, et al. Improving foot care for people with diabetes mellitus--a randomized controlled trial of an integrated care approach. Diabet Med. 2000;17(8):581-587.

29. Dorresteijn JA, Kriegsman DM, et al. Patient education for preventing diabetic foot ulceration. Cochrane Database Syst Rev. 2014;16:12. 